\title{
Isolation and characterization of major histocompatibility complex (MHC) class II B genes in the Barn owl (Aves: Tyto alba)
}

\author{
Reto Burri • Hélène Niculita-Hirzel • Alexandre Roulin • \\ Luca Fumagalli
}

Received: 22 February 2008 / Accepted: 19 May 2008 / Published online: 12 June 2008

(C) Springer-Verlag 2008

\begin{abstract}
We isolated major histocompatibility complex class II B (MHCIIB) genes in the Barn owl (Tyto alba). A PCR-based approach combined with primer walking on genomic and complementary DNA as well as Southern blot analyses revealed the presence of two MHCIIB genes, both being expressed in spleen, liver, and blood. Characteristic structural features of MHCIIB genes as well as their expression and high non-synonymous substitution rates in the region involved in antigen binding suggest that both genes are functional. MHC organization in the Barn owl is simple compared to passerine species that show multiple duplications, and resembles the minimal essential MHC of chicken.
\end{abstract}

Keywords MHC class II · Avian MHC · Positive selection · Concerted evolution · Tyto alba

Data deposition: Nucleotide sequence data reported in this paper have been deposited in the GenBank database and have accession numbers EU442602-EU442607.

Electronic supplementary material The online version of this article (doi:10.1007/s00251-008-0308-0) contains supplementary material, which is available to authorized users.

R. Burri $(\bowtie) \cdot$ L. Fumagalli

Laboratory for Conservation Biology, Department of Ecology

and Evolution, Biophore, University of Lausanne,

1015 Lausanne, Switzerland

e-mail: reto.burri@unil.ch

H. Niculita-Hirzel $\cdot$ A. Roulin

Department of Ecology and Evolution, Biophore,

University of Lausanne,

1015 Lausanne, Switzerland

\section{Introduction}

Genes of the major histocompatibility complex (MHC) are placed among the best candidates for the study of adaptive genetic diversity. The cell-surface proteins encoded by MHC class I bind antigens derived from intra-cellular pathogens, such as viruses, whereas class II molecules bind antigens derived from extra-cellular pathogens. Their important role in the activation of the adaptive immune response links MHC genes directly to individual fitness. Moreover, MHC genes exhibit the highest levels of polymorphism known to date for vertebrates, with human populations exhibiting over 500 alleles at a single locus (Robinson et al. 2003). This high level of polymorphism is maintained by balancing selection resulting from heterozygote or rare-allele advantage (Takahata and Nei 1990), as the ability of MHC genes to screen broad arrays of pathogens is related to a high allelic sequence variation in the region coding for the antigen binding sites (ABS) (Doherty and Zinkernagel 1975).

Despite a growing body of empirical data, the role of pathogens in maintaining a high level of MHC diversity in natural populations is still debated and needs further investigation (Penn et al. 2002; Zelano and Edwards 2002; Milinski 2006; Piertney and Oliver 2006). Elucidation of these issues calls for the isolation of MHC markers in non-model species, which however until recently was hampered by the tremendous inter-specific variation in MHC architecture. Since species vary considerably in the number of functional and non-functional MHC genes, an important prerequisite to study MHC diversity is to know how many duplications of MHC genes are present in the species of interest, and whether or not these loci are expressed.

Here, we isolated and characterized MHC class II B genes in the Barn owl (Tyto alba). Given its worldwide distribution 
(Del Hoyo et al. 2000), the species presumably is exposed to a variety of pathogens. Furthermore, this bird can display assortative mating with respect to an ornamental trait that is associated to parasite resistance and offspring fitness (Roulin 1999; Roulin et al. 2001, 2003), all pointing to still unanswered questions upon the role of pathogen-driven and sexual selection in the maintenance of MHC diversity.

\section{Materials and methods}

DNA extraction, RNA extraction, and reverse transcription

Total genomic DNA was extracted from blood from five Swiss Barn owls (Tyto alba, Tytonidae, Strigiformes) using the DNeasy Tissue Kit (Qiagen, Switzerland). For expression analysis, total RNA was isolated from the spleen and liver obtained from a Swiss Barn owl roadkill frozen at $-20^{\circ} \mathrm{C}$ immediately after collection and from three individuals' blood stored on liquid nitrogen directly after sampling, using TRIzol (Invitrogen, Switzerland). After DNase treatment using the RNeasy Mini Kit (Qiagen), first-strand cDNA was synthesized from $1 \mu \mathrm{g}$ of total RNA using the SuperScript ${ }^{\mathrm{TM}}$ III Reverse Transcriptase (Invitrogen).

\section{Isolation of MHC class II B genes}

Primers used to amplify MHCIIB exon 2 in other avian species were aligned with MHCIIB sequences of diverse bird species, Spectacled caiman (Caiman crocodilus, accession no. AF256652) and human (accession no. NM_002124). Primers pen-1 and pen-4 (Table 1, Tsuda et al. 2001), which matched the conserved regions in exon 2 best, were applied in initial PCR reactions on genomic DNA. PCR reactions were carried out on a Biometra T1 gradient thermocycler in a final volume of $25 \mu$ containing $1 \times$ buffer Gold $10 \times, 2.0 \mathrm{mM} \mathrm{MgCl}_{2}, 0.2 \mathrm{mM}$ dNTP, $0.5 \mu \mathrm{M}$ each primers, and $2 \mathrm{U}$ AmpliTaq Gold (Applied Biosystems, Switzerland). PCR conditions included an initial denaturation step at $95^{\circ} \mathrm{C}$ for $5 \mathrm{~min}, 35$ cycles of denaturation at $95^{\circ} \mathrm{C}$ for $1 \mathrm{~min}$, primer annealing at $55^{\circ} \mathrm{C}$ for $1 \mathrm{~min}$, and primer extension at $72^{\circ} \mathrm{C}$ for $2 \mathrm{~min}$. A final step at $72^{\circ} \mathrm{C}$ for $7 \mathrm{~min}$ was used to complete primer extension. To confirm transcription of the gene, a PCR applying the same conditions as above with an annealing temperature of $54^{\circ} \mathrm{C}$ was carried out on cDNA. Amplicons of both genomic DNA and cDNA were run on a $2 \%$ agarose gel. Bands of expected size were excised and purified using the QIAquick Gel Extraction Kit (Qiagen), and sequenced directly.

In order to isolate the entire gene sequence, we applied a primer walking strategy, starting from exon 2 (for primers see Supplementary Material Table S1). First, the Genome Walker ${ }^{\mathrm{TM}}$ Kit (BD Biosciences Clontech, Germany) was applied in both 5'- and 3'-direction on genomic DNA. Candidate bands were sequenced directly and cloned using the pGEM $^{\circledR}$-T Easy Vector System (Promega, Switzerland). This method was successful in 5'-direction and yielded a

Table 1 Primers used for amplification of MHCIIB genes in Barn owls

\begin{tabular}{|c|c|c|c|c|}
\hline Primer & Sequence & Locus/allele & PCR & Reference \\
\hline pen-1 & AAC GGC ACC GAG CGG GYG AGG T & Tyal-DAB1 & $\begin{array}{l}\text { Exon 2: initial PCR } \\
\text { on gDNA and cDNA/Exon } \\
2-3 \text { on cDNA }\end{array}$ & $\begin{array}{l}\text { Tsuda et al. } 2001 \\
\text { (slightly modified) }\end{array}$ \\
\hline pen-4 & CCC GTA GTT GTG TTG GCA G & Tyal-DAB1 & $\begin{array}{l}\text { Exon 2: initial PCR } \\
\text { on gDNA and cDNA }\end{array}$ & Tsuda et al. 2001 \\
\hline EX3R-aves & AGC ACC TGG TAG GTC CAG TC & Tyal-DAB1/2 & Exon $2-3$ on cDNA & $\begin{array}{l}\text { Ekblom et al. } 2003 \\
\text { (slightly modified) }\end{array}$ \\
\hline Tyal-ex1F & $\begin{array}{l}\text { TGT GGG GGG AGT TGG GGC TGT } \\
\text { GCT G }\end{array}$ & Tyal-DAB1/2 & Exon $1-3$ on cDNA/intron 1 & Present study \\
\hline Tyal-ex3-3'R & AGG CTG ACG TGC TCC ACC TG & Tyal-DAB1/2 & Exon $1-3$ on cDNA & Present study \\
\hline Tyal-int1F & CCA TGA CCG ACC TCC CTA TG & Tyal-DAB1 & $\begin{array}{l}\text { Exon } 2 \text { DAB1 on gDNA/ } \\
\text { introns } 2 \text { and } 3\end{array}$ & Present study \\
\hline Tyal-ex2R & AAA CCT CAT AGT TGT GTC GGC AG & Tyal-DAB1/2 & Exon 2 on gDNA and cDNA & Present study \\
\hline $\mathrm{DAB} 1 * 01 \mathrm{R}$ & TCC ACT GCG GCT CTT TTA CG & Tyal-DAB $1 * 01$ & Allele-specific PCR & Present study \\
\hline $\mathrm{DAB} 1 * 04 \mathrm{R}$ & TCC ACC GCG GCT CTT GCA TC & Tyal-DAB1*04 & Allele-specific PCR & Present study \\
\hline Tyal-DAB2-F & $\begin{array}{l}\text { ATA TCC AGT TCC AGT TTA AGG } \\
\text { GCG }\end{array}$ & Tyal-DAB2*01 & $\begin{array}{l}\text { Locus-specific PCR/introns } \\
2 \text { and } 3\end{array}$ & Present study \\
\hline Tyal-DAB2-R & TGT AGT TGT TTC GGC AGA CC & Tyal-DAB $2 * 01$ & Locus-specific PCR & Present study \\
\hline Tyt-DAB1-int1R & CTG TTT GCA TAG GGA GGT CGG TC & Tyal-DAB1 & Intron 1 & Present study \\
\hline Tyt-DAB2-ex2R & GTC GCC CTT AAA CTG GAA CTG G & Tyal-DAB2 & Intron 1 & Present study \\
\hline Tyal-ex4R & $\begin{array}{l}\text { GAG TCC CAG CAC GAA GCC CCC } \\
\text { CAC }\end{array}$ & Tyal-DAB1/2 & Introns 2 and 3 & Present study \\
\hline
\end{tabular}


sequence extended into intron 1 . To extend the sequence, we used the PCR-based DNA Walking SpeedUp ${ }^{\text {TM }}$ Premix Kit (Seegene, Korea). Primers designed from intron 1 and exon 2 were used to walk in the $5^{\prime}$ - and $3^{\prime}$-direction, respectively. Direct sequencing of the resulting bands yielded a sequence encompassing intron 1 and exon 1 up to the putative start codon.

As primer walking on genomic DNA was not successful in 3'-direction, the next steps were performed on cDNA. Primers pen-1 and EX3R-aves (Table 1), situated in exons 2 and 3 respectively, were applied in a PCR with the conditions indicated above. Based on the obtained sequence, primers situated in exon 3 were designed and applied in 3'-direction with the DNA Walking Speed $U p^{\mathrm{TM}}$ Premix Kit. Direct sequencing of the candidate bands yielded the lacking part of the coding sequence down to the putative stop codon.

RT-PCR, cloning, and intron isolation

For the isolation of introns, information on polymorphic sites in exon 2 and exon 3 was needed to construct primers situated in conserved exon regions. To obtain allelic sequences of exon 2 and exon 3, we therefore designed primers Tyal-ex1F in exon 1 and Tyal-ex3-3' $\mathrm{R}$ in exon 3 (Table 1). RT-PCR was performed for four individuals with the conditions indicated above and an annealing temperature of $68^{\circ} \mathrm{C}$. Amplicons were migrated on a $1 \%$ agarose gel. Bands of expected length were excised, purified with the QIAquick Gel Extraction Kit (Qiagen), and cloned using the pGEM ${ }^{\circledR}-T$ Easy Vector System (Promega). Ten positive clones per individual were sequenced.

To isolate intron 1, we used primer pairs Tyal-ex1F/TytDAB1-int1R and Tyal-ex1F/Tyt-DAB2-ex2R (Table 1). Tyal-int1F/Tyal-ex4R and Tyal-DAB2-F/Tyal-ex4R (Table 1) were used to isolate introns 2 and 3. PCR reactions were done on a Biometra $\mathrm{T} 1$ gradient thermocycler in a final volume of $25 \mu$ containing $1 \times$ buffer Gold $10 \times, 2.0 \mathrm{mM}$ $\mathrm{MgCl}_{2}, 1 \times \mathrm{Q}$ Solution (Qiagen), $0.2 \mathrm{mM} \mathrm{dNTP}, 0.5 \mu \mathrm{M}$ each primers, and $1 \mathrm{U}$ AmpliTaq Gold (Applied Biosystems). PCR conditions included an initial denaturation step at $95^{\circ} \mathrm{C}$ for $7 \mathrm{~min}, 35$ cycles of denaturation at $95^{\circ} \mathrm{C}$ for $40 \mathrm{~s}$, primer annealing at primer specific annealing temperatures for $40 \mathrm{~s}$, and primer extension at $72^{\circ} \mathrm{C}$ for $2 \mathrm{~min}$. Annealing temperatures were $58^{\circ} \mathrm{C}$ and $68^{\circ} \mathrm{C}$ for intron 1 and intron $2 / 3$ PCRs, respectively. A final step at $72^{\circ} \mathrm{C}$ for 7 min was used to complete primer extension.

\section{Southern blot analyses}

The MHC is characterized by high rates of gene duplication and pseudo-gene formation. To obtain an overview of the number of MHCIIB genes present in the Barn owl, we thus performed a Southern blot analysis. High molecular weight DNA was extracted from the liver of the individual used in primer walking, using the DNeasy Tissue Kit (Qiagen). DNA was digested overnight with one of the five enzymes AleI, AflIII, Bsu36I, EcoRI, and SacI (see Fig. 1). Ten micrograms of digested DNA was migrated on a $1 \%$ agarose gel in TBE buffer for up to $20 \mathrm{~h}$ at $1.14 \mathrm{~V} / \mathrm{cm}$ and then transferred to a nylon membrane by Southern blotting. Two probes were constructed from a cDNA clone, using primer combinations pen-1/Tyal-ex $2 \mathrm{R}$ (exon 2 probe) and Tyal-ex3-3' F/Tyal-ex3-5' R (exon 3 probe). Probes were marked with DIG-dUTP using the PCR DIG Probe Synthesis Kit (Roche) and purified from gel using the QIAquick Gel Extraction Kit (Qiagen). Hybridization was carried out overnight in DIG easy Hyb (Roche) at optimal temperature $\left(45^{\circ} \mathrm{C}\right)$. Membranes were washed twice $5 \mathrm{~min}$ in $2 \times$ standard saline citrate (SSC) $/ 0.1 \%$ sodium dodecyl sulfate (SDS) at room temperature and twice in $0.5 \times \mathrm{SSC} /$ $0.2 \% \mathrm{SDS}$ at $65^{\circ} \mathrm{C}$ for $15 \mathrm{~min}$ and then exposed $5 \mathrm{~h}$ to overnight to Kodak Biomax MR film.

Sequence analyses

Sequences were assembled in Aligner 2.0.1 (CodonCode) and aligned using the ClustalW algorithm. Cloned cDNA

a)

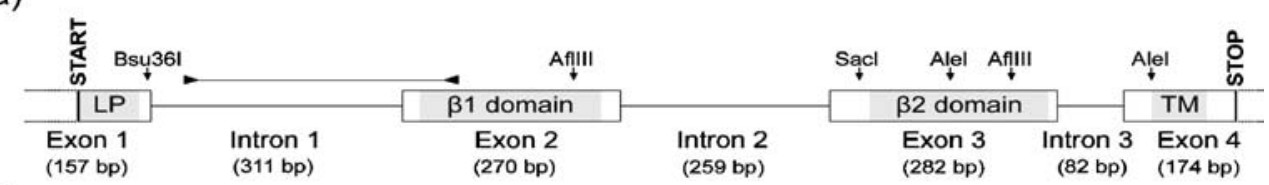

b)

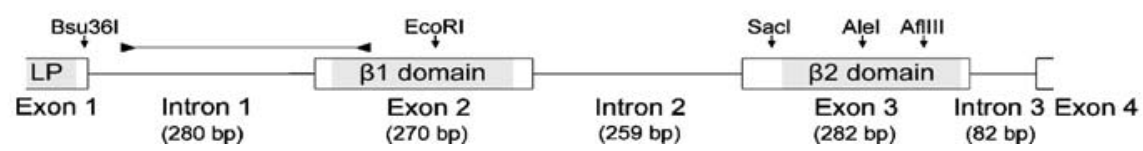

Fig. 1 Schematic illustration and restriction maps of the Barn owl MHCIIB genes Tyal-DAB1 (a) and Tyal-DAB2 (b). Boxes represent exons. Functional domains are indicated in light grey. The highly divergent regions encompassing intron 1 and the region of exon 2

containing the 18-bp locus signature are indicated by horizontal lines delimited by arrow heads. $L P$, leader peptide; TM, trans-membrane domain 
sequences were cross-checked with the ones from uncloned PCR products, and only those represented by more than one clone were considered in further analyses.

To confirm the identity of the coding sequence isolated from Barn owl, we performed BLAST searches with nucleotide (megablast) and protein sequences (blastp). CD-Search (Marchler-Bauer and Bryant 2004) and SMART (Schultz et al. 1998) were used to identify signaling domains. Additionally, sequences were manually checked for features typical to functional MHCIIB genes, like the intra-domain cysteine salt bridges, the conserved glycosylation site (NGT) in the $\beta 1$ domain, the conserved residues in the $\beta 1$ domain characteristic of classical MHCIIB molecules (Kaufman et al. 1994), and the conserved residues implicated in CD4 binding in the human DRB molecule (Wang et al. 2001). For each intron, BLAST searches (blastn) were done separately.

Mean pairwise differences between sequences $(\pi)$ were calculated in Arlequin 3.0 (Excoffier et al. 2005). Analyses of selection were performed in CodeML (Yang and Nielsen 2000). To test for differences of selective pressures among sites in exon 2 and identify those sites that were potentially under positive selection, we performed maximum likelihood (ML) ratio tests comparing model M1a with M2a and model M7 with M8. Models M1a and M7 are neutral, while models M2a and M8 allow for a proportion of sites under positive selection. For a detailed description of these models see Nielsen and Yang (1998) and Yang and Nielsen (2000).

\section{Results}

Isolation and characterization of MHC class II B genes

Making use of a PCR-based approach combined with primer walking on genomic and complementary DNA, we isolated two functional MHCIIB genes (accession numbers of isolated sequences at GenBank are EU442602EU442607). According to Klein et al. (1990), we designated those two loci, MhcTyal-DAB1 and MhcTyal-DAB2, with alleles denoted by the gene name followed by an asterisk and sequential allele numbers. The two genes are highly similar over large stretches, including introns 2 and 3. However, they are distinguished by the highly divergent intron 1 and a locus-specific $18 \mathrm{bp}$ signature within the first 70 nucleotide sites of exon 2 (see below, Figs. 1 and 2). Mean pairwise differences between cloned sequences from the different loci were $49.00 \pm 2.73$, and are significantly larger between than within loci when the locus signature is considered (Kruskal-Wallis test, $p<0.01$ ) and marginally significant when the 18 nucleotide sites of the signature are removed (Kruskal-Wallis test, $p=0.06$ ).
The coding sequence of Tyal-DAB1 encompasses $783 \mathrm{bp}$ (261 amino acid residues) from start to stop codon and is partitioned among four exons (Fig. 1). For TyalDAB2, 652 bp of coding sequence (217 amino acid residues) were obtained by PCR.

Expression analyses for the two loci were performed through RT-PCR. Sequencing of the cloned RT-PCR products from four individuals resulted in a total of six alleles, i.e., four for Tyal-DAB1 and two for Tyal-DAB2. Their successful amplification from spleen, liver, and blood shows that both genes are expressed in all these tissues.

Protein-protein BLAST searches produced significant hits with known avian and mammalian MHCIIB protein sequences. Tyal-DAB1 and Tyal-DAB2 proteins contain the features expected for classical MHCIIB molecules (Fig. 2). CD-Search (Marchler-Bauer and Bryant 2004) identified a $\beta 1$ domain in exon 2 and a IGc1 domain in exon 3 (Figs. 1 and 2). SMART confirmed these domains, and identified a signal peptide and a trans-membrane domain (Figs. 1 and 2 ). The trans-membrane domain was confirmed by the TMpred (Hofmann and Stoffel 1993) and Phobius softwares (Kall et al. 2004). The manual survey confirmed the conserved intra-domain cysteine salt bridges within $\beta 1$ and $\beta 2$ domains. In the conserved glycosylation site (NGT), the threonine is replaced conservatively (Hanada et al. 2007) by a serine. All but two of the conserved residues in the $\beta 1$ domain characteristic of classical MHCIIB molecules (Kaufman et al. 1994) are conserved, as are the conserved residues implicated in CD4 binding in the human DRB molecule (Wang et al. 2001).

Positive selection on the sites involved in antigenbinding is expected to result in considerable variation in exon 2 of functional MHCIIB genes. We therefore estimated variability in the cloned sequences and tested if positive selection was acting on the Barn owl MHCIIB. Cloning yielded four Tyal-DAB1 alleles and two TyalDAB2 alleles. Exon 2 harbors most of the polymorphic sites within and among genes $(92 \%, 65$ out of 71 sites). About half (31 sites) are located in sites corresponding to human ABS (Brown et al. 1993). Mean pairwise differences between alleles were $35.37 \pm 17.78$ overall, $21.83 \pm$ 12.28 within Tyal-DAB1 and six between Tyal-DAB2 alleles. ML analyses show that positive selection is acting on the Barn owl MHC. They reveal considerable variation in selective pressures among sites in exon 2. Seven sites were detected (M2a, $\omega=11.73 \pm 0.20)$ that are under positive selection, of which six correspond to human ABS (Brown et al. 1993; however, for an alternative model of antigen binding see Tong et al. 2006) (Fig. 3).

Using locus-specific primers situated in exons, we successfully amplified all introns of both Tyal-DAB genes. Introns vary from $82 \mathrm{bp}$ (intron 3) to $311 \mathrm{bp}$ (DAB1 intron 1) in length (Fig. 1), and all contain the classical splicing 
Fig. 2 Amino acid alignment of Barn owl MHCIIB sequences with chicken B-Lb I (Gallus gallus, accession no. AL023516) and Tuatara (Sphenodon punctatus, accession no. DQ124232). Dots indicate identity with the Tyal-DAB $1 * 01$ sequence; dashes indicate gaps. Exon boundaries are indicated by black arrow heads and exon number. Conserved residues characteristic of classical MHCIIB chain molecules (Kaufman et al. 1994) and highly conserved residues in exon 3 implicated in CD4 binding in humans (Wang et al. 2001) are shaded. Cysteine bridges in the $\beta 1$ and $\beta 2$ domains are indicated by brackets
T. alba DRB1*01

T. alba DRB1*02

T. alba DRB1*03

$T$. alba DRB1*04

T. alba DRB2*01

$T$. alba DRB2*02

G. gallus B-Lbl

S. punctatus

T. alba DRB1*01

T. alba DRB1*02

T. alba DRB1*03

T. alba DRB1*04

$T$. alba DRB2*01

T. alba DRB2*02

G. gallus B-Lbl

S. punctatus

T. alba DRB1*01

T. alba DRB1*02

$T$. alba DRB1*03

$T$. alba DRB1*04

T. alba DRB2*01

T. alba DRB2*02

G. gallus B-LbI

S. punctatus

T. alba DRB1*01

$T$. alba DRB1*02

T. alba DRB1*03

$T$. alba DRB1*04

T. alba DRB2*01

T. alba DRB2*02

G. gallus B-Lbl

S. punctatus

T. alba DRB1*01

T. alba DRB1*02

$T$. alba DRB1*03

$T$. alba DRB1*04

T. alba DRB2*01

$T$. alba DRB2*02

G. gallus B-LbI

S. punctatus $\checkmark 1$ Leader peptide $>2 \quad \beta 1$ domain MEPARVGGVGAVLVALVVLGAHP--ARGEQTSEVFQEYGESECOFFNGSERVRFVERYIY ---

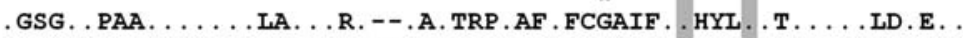
AGSRWA . APLL . MLL . LLP . LR . LL . H . AEPP . H . LYQAKAQ . LYPD. TG . I . YLK . YW
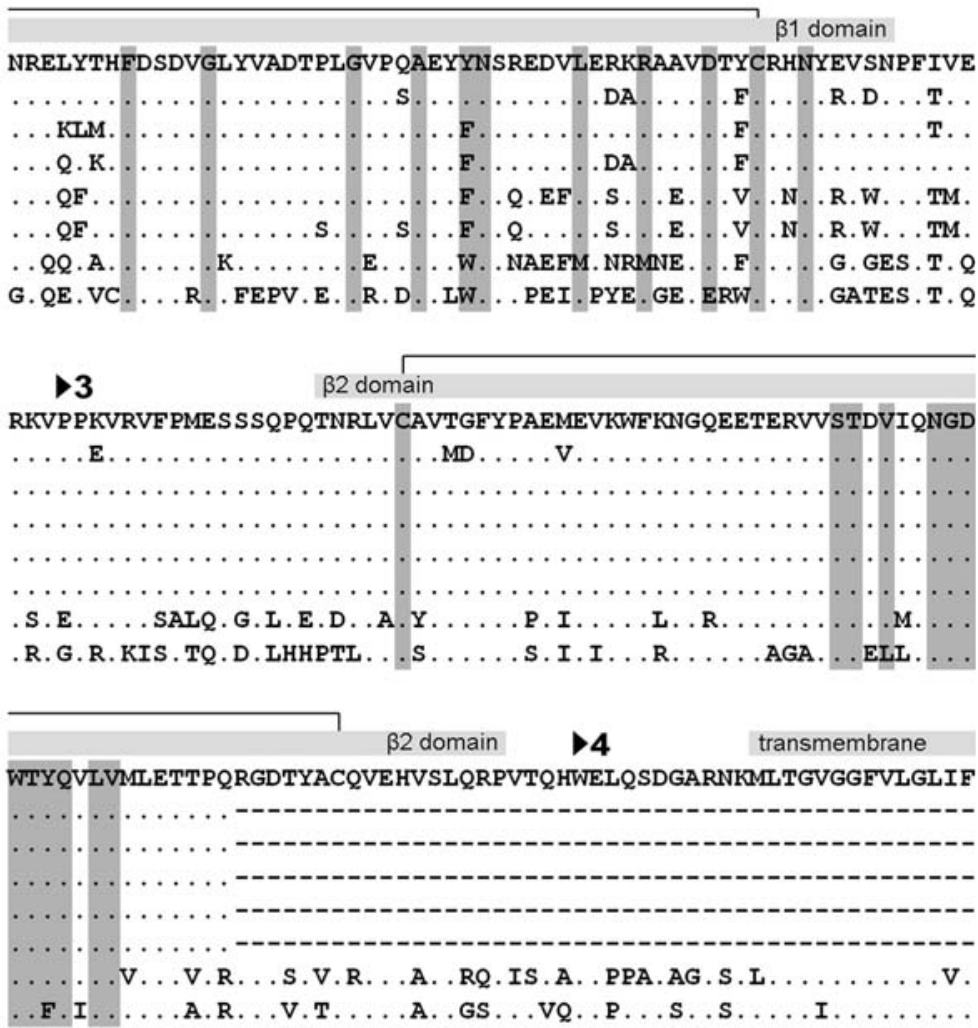

transmembrane

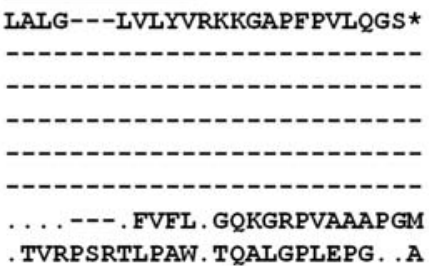

signal 5'-GT-intron-AG-3'. Introns 2 and 3 are identical between Tyal-DAB genes. Intron 1 is identical at only the first 40 nucleotide sites and completely divergent between genes for the rest of its sequence, and $32 \mathrm{bp}$ longer in TyalDAB1 than in Tyal-DAB2 (Figs. 1 and S1).

Number of MHCIIB genes in the Barn owl

To confirm the presence of the two genes isolated by PCR and primer walking and obtain an estimate for the number of MHCIIB genes present in Barn owl, we performed simple PCR-based tests and Southern blot analyses. The presence of the two genes Tyal-DAB1 and Tyal-DAB2 was confirmed by successful locus- and allele-specific PCR reactions in the individual on which the isolation was performed (for primers see Table 1). Southern blot analyses confirmed this result and gave no indication for the presence of further MHCIIB genes (Fig. 4). The number of detected fragments corresponded to fragments predicted from the restriction map (Fig. 1), except for the hybridiza- 


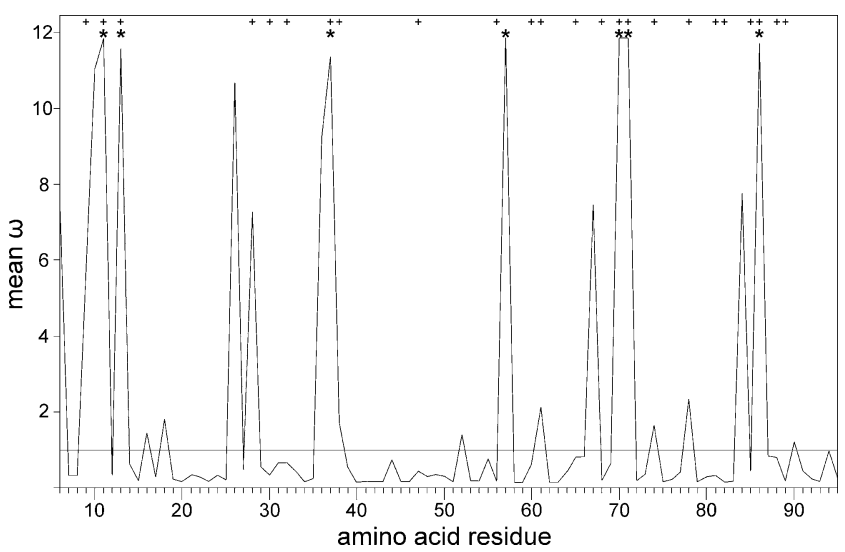

Fig. 3 Mean $\omega\left(\mathrm{d}_{\mathrm{N}} / \mathrm{d}_{\mathrm{S}}\right)$ along the Barn owl MHCIIB exon 2 sequence as calculated in CodeML (model M2a). The horizontal line denotes a $\omega$ of 1 , indicating neutral evolution. Residue numbers are given according to Brown et al. (1993). * Sites identified to be under positive selection in Barn owl. Significance was tested by the BEB procedure. + Sites corresponding to human antigen-binding sites (Brown et al. 1993)

tion of the EcoRI restriction with the exon 3 probe that produced a single band, while two were expected. The presence of only one band in this hybridization could be due to an approximately equal length of the fragments expected for the two genes or to a tandem architecture with Tyal-DAB2 in 5'-position of Tyal-DAB1. The weakness of three bands in AflIII-restricted DNA and of the short fragment in the AleI restriction can be explained by small overlaps of these fragments with the probes. Results for AleI, AflIII, and EcoRI are shown in Fig. 4; those for Bsu36I and SacI confirmed the first three and are not shown.

\section{Discussion}

Genomic organization of the Barn owl MHCIIB

Using PCR-based and Southern blot analyses, we isolated and characterized two MHCIIB genes in the Barn owl. As recently demonstrated, these genes are orthologs of Strigidae owl and Great snipe (Gallinago media) MHCIIB genes (Burri et al. 2008). Several observations are consistent with the hypothesis that both loci are functional: (1) they are expressed in several tissues; (2) show high non-synonymous substitution rates indicative of positive selection; (3) have no frameshift mutations and stop codons. This provides strong evidence for a simple genomic organization of the Barn owl MHCIIB, similar to the simple chicken MHCIIB (Zoorob et al. 1990; Kaufman et al. 1999). Our results thus constitute the first conclusive support for the suggestion made by Alcaide et al. (2007) that in birds of prey MHC organization might be simple. These authors applied a PCR-based survey, admitting that such an approach is prone to the underestimation of the number of genes (Wagner et al. 1994). Accordingly, for the Barn owl, their approach confirmed our genomic sequence of TyalDAB1 but did not detect the presence of Tyal-DAB2.

\section{Concerted evolution of the Barn Owl MHCIIB}

Concerted evolution has acted to a limited extent between Tyal-DAB genes, contrary to most avian species (Hess and Edwards 2002). Tyal-DAB genes are highly similar over most of their sequence, presumably owing to homogenization by gene conversion. However, 340 nucleotide sites, comprising intron 1 and 70 nucleotide sites of exon 2 (Figs. 1 and S1), seem to have escaped concerted evolution so far. These positions differ substantially between TyalDAB1 and Tyal-DAB2. Despite the high overall divergence of intron 1 between the two genes, this intron's first 40 nucleotide sites are identical. Moreover, this region is the most conserved in intron 1 among all birds of prey (Fig. S1), among songbirds, and among chicken and pheasant (Wittzel et al. 1994; Edwards et al. 1998). The inter-specific conservation was previously interpreted in terms of selective constraints, concerted evolution, or recent duplication (Wittzel et al. 1994; Edwards et al. 1998). It seems unlikely that selective constraints result from selection on the intron itself. Given the frequency of

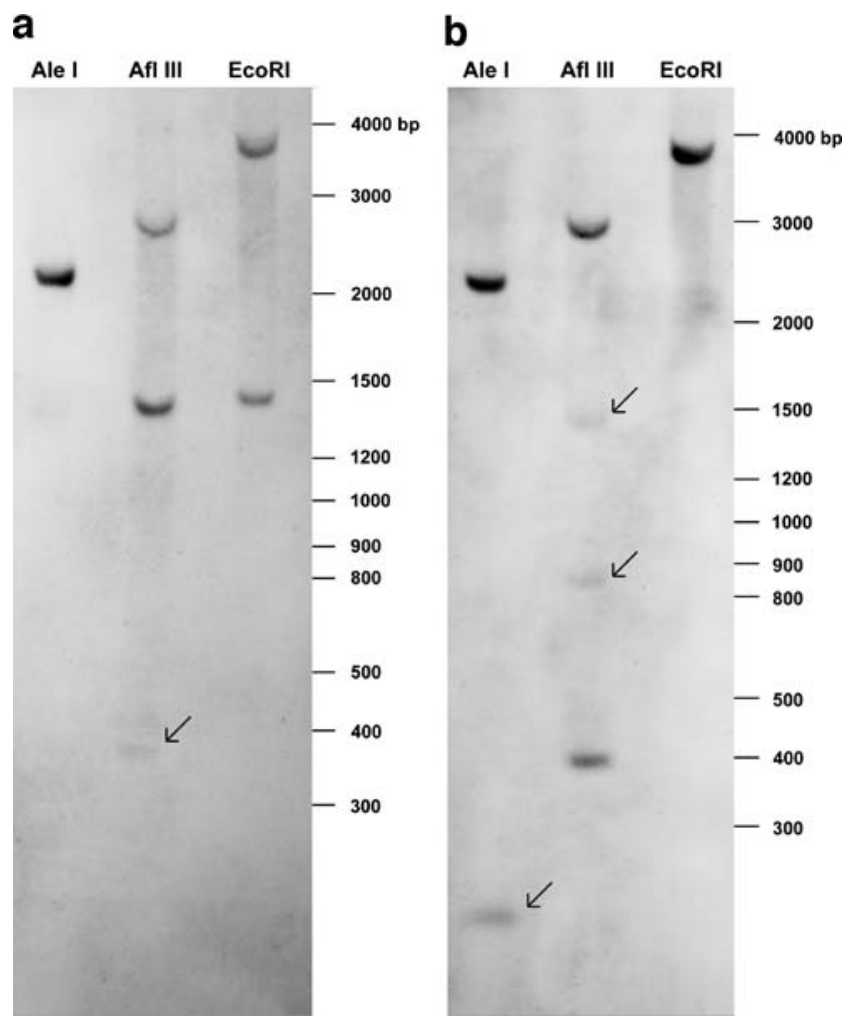

Fig. 4 Banding pattern for the Southern blot analyses with the exon 2 (a) and the exon 3 (b) probes. Flashes highlight weak bands 
deletions in the intron 1 of birds of prey (Fig. S1), the conservation of the exon-flanking sequences might rather represent a byproduct of selection eliminating deletions reaching into exon 2. Most probably, however, it might also be a result of convergent evolution.

\section{MHC evolutionary ecology}

The study of the MHC evolutionary ecology in birds is usually hampered by the presence of multiple gene duplicates, and typically alleles cannot be attributed to loci (Hess and Edwards 2002). Therefore, studies considering only a subset of the loci present in a given species may miss important information or suffer from low statistical power, and data from non-functional loci may even yield misleading results. The present study provides the essential basics for immunogenetic studies in the Barn owl. The low number of loci found in this species allows for studies considering the complete individual MHCIIB genotypes. Together with the possibility to attribute the alleles to specific loci, this will strongly facilitate the study of MHC evolutionary ecology in the Barn owl compared to most avian species.

Acknowledgements We thank Catherine Berney for technical assistance in the lab, Anne-Lyse Ducrest for helpful discussions, Philippe Christe for providing samples, and two anonymous reviewers for helpful comments on earlier versions of the manuscript. The study was supported by the Swiss National Science Foundation grants 3100A0-109852/1 to LF and PP00A-102913 to AR.

\section{References}

Alcaide M, Edwards S, Negro J (2007) Characterization, polymorphism, and evolution of MHC Class II B genes in birds of prey. J Mol Evol 65:541-554

Brown JH, Jardetzky TS, Gorga JC, Stern LJ, Urban RG, Strominger JL et al (1993) Three-dimensional structure of the human class II histocompatibility antigen HLA-DR1. Nature 364:33-39

Burri R, Niculita-Hirzel H, Salamin N, Roulin A, Fumagalli L (2008) Evolutionary patterns of MHC class II B in owls and their implications for the understanding of avian MHC evolution. Mol Biol Evol 25:1180-1191

Del Hoyo J, Elliott A, Sargatal J (2000) Barn owls to hummingbirds. Handbook of the birds of the world. Lynx Editions, Barcelona, p 759

Doherty PC, Zinkernagel RM (1975) Enhanced immunological surveillance in mice heterozygous at the $\mathrm{H}-2$ gene complex. Nature 256:50-52

Edwards S, Gasper J, March M (1998) Genomics and polymorphism of Agph-DAB1, an Mhc class II B gene in red-winged blackbirds (Agelaius phoeniceus). Mol Biol Evol 15:236-250

Ekblom R, Grahn M, Höglund J (2003) Patterns of polymorphism in the MHC class II of a non-passerine bird, the great snipe (Gallinago media). Immunogenetics 54:734-741

Excoffier L, Laval G, Schneider S (2005) Arlequin (version 3.0): an integrated software for population genetics data analysis. Evol Bioinformatics 1:47-50
Hanada K, Shiu S-H, Li W-H (2007) The nonsynonymous/synonymous substitution rate ratio versus the radical/conservative replacement rate ratio in the evolution of mammalian genes. Mol Biol Evol 24:2235-2241

Hess CM, Edwards SV (2002) The evolution of the major histocompatibility complex in birds. Bioscience 52:423-431

Hofmann K, Stoffel W (1993) TMbase - a database of membrane spanning proteins segments. Biol Chem Hoppe Seyler 374:166

Kall L, Krogh A, Sonnhammer ELL (2004) A combined transmembrane topology and signal peptide prediction method. J Mol Biol 338:1027-1036

Kaufman J, Milne S, Gobel TWF, Walker BA, Jacob JP, Auffray C et al (1999) The chicken B locus is a minimal essential major histocompatibility complex. Nature 401:923-925

Kaufman J, Salomonsen J, Flajnik M (1994) Evolutionary conservation of MHC class I and class II molecules-different yet the same. Semin Immunol 6:411-424

Klein J, Bontrop R, Dawkins RL, Erlich HA, Gyllensten UB, Heise ER et al (1990) Nomenclature for major histocompatibility complexes of different species: a proposal. Immunogenetics 31:217-219

Marchler-Bauer A, Bryant SH (2004) CD-Search: protein domain annotations on the fly. Nucleic Acids Res 32:W327-W331

Milinski M (2006) The major histocompatibility complex, sexual selection, and mate choice. Annu Rev Ecol Evol Syst 37:159-186

Nielsen R, Yang Z (1998) Likelihood models for detecting positively selected amino acid sites and applications to the HIV-1 envelope gene. Genetics 148:929-936

Penn DJ, Damjanovich K, Potts WK (2002) MHC heterozygosity confers a selective advantage against multiple-strain infections. Proc Natl Acad Sci USA 99:11260-11264

Piertney SB, Oliver MK (2006) The evolutionary ecology of the major histocompatibility complex. Heredity 96:7-21

Robinson J, Waller MJ, Parham P, de Groot N, Bontrop R, Kennedy LJ et al (2003) IMGT/HLA and IMGT/MHC: sequence databases for the study of the major histocompatibility complex. Nucleic Acids Res 31:311-314

Roulin A (1999) Nonrandom pairing by male Barn owls (Tyto alba) with respect to a female plumage trait. Behav Ecol 10:688-695

Roulin A, Ducrest A-L, Balloux F, Dijkstra C, Riols C (2003) A female melanin ornament signals offspring fluctuating asymmetry in the Barn owl. P Roy Soc B-Biol Sci 270:167-171

Roulin A, Riols C, Dijkstra C, Ducrest A-L (2001) Female plumage spottiness signals parasite resistance in the Barn owl (Tyto alba). Behav Ecol 12:103-110

Schultz J, Milpetz F, Bork P, Ponting CP (1998) SMART, a simple modular architecture research tool: identification of signaling domains. Proc Natl Acad Sci USA 95:5857-5864

Takahata N, Nei M (1990) Allelic genealogy under overdominant and frequency-dependent selection and polymorphism of major histocompatibility complex loci. Genetics 124:967-978

Tong JC, Bramson J, Kanduc D, Chow S, Sinha AA, Ranganathan S (2006) Modeling the bound conformation of Pemphigus vulgarisassociated peptides to MHC class II DR and DQ alleles. Immunome Res 2:1

Tsuda T, Tsuda M, Naruse T, Kawata H, Ando A, Shiina T et al (2001) Phylogenetic analysis of penguin (Spheniscidae) species based on sequence variation in MHC class II genes. Immunogenetics 53:712-716

Wagner A, Blackstone N, Cartwright P, Dick M, Misof B, Snow P et al (1994) Surveys of gene families using polymerase chain reaction: PCR selection and PCR drift. Syst Biol 43:250-261

Wang J-H, Meijers R, Xiong Y, Liu J-h, Sakihama T, Zhang R et al (2001) Crystal structure of the human CD4 N-terminal twodomain fragment complexed to a class II MHC molecule. Proc Natl Acad Sci USA 98:10799-10804 
Wittzel H, von Schantz T, Zoorob R, Auffray C (1994) Molecular characterization of three Mhc class II B haplotypes in the ringnecked pheasant. Immunogenetics 39:395-403

Yang Z, Nielsen R (2000) Estimating synonymous and nonsynonymous substitution rates under realistic evolutionary models. Mol Biol Evol 17:32-43
Zelano B, Edwards SV (2002) An Mhc component to kin recognition and mate choice in birds: predictions, progress, and prospects. Am Nat 160:S225-S237

Zoorob R, Béhar G, Kroemer G, Auffray C (1990) Organisation of a functional chicken class II B gene. Immunogenetics 31:179187 